\title{
Correspondence
}

\section{Medical evidence in child abuse cases}

Sir,

The letter by Hall et al would be an interesting response to a claim that speech delay in the absence of any other evidence of child abuse is a sufficient reason for action in the courts. ${ }^{1}$ Our paper says nothing of the kind. ${ }^{2}$ We were at pains to associate speech delay with other evidence of abuse, and it is implicit in our comments that inferring a link between speech delay and abuse requires evidence that the child has been in a depriving, neglectful, and understimulating environment. The problem with which we were trying to grapple is that for the medical witness such evidence is often secondhand and therefore may be regarded as hearsay, hence the need for inference. It is the role of the social worker to tell the court what home circumstances are like. If there is no evidence of adverse home circumstances and/or additional signs of abuse, such as failure to thrive or non-accidental injury, the case could not be taken to court in the first place nor would any sensible court make an order. To quote from our article:

'Thus, while it is not possible, for example, to say that a child with speech delay must be neglected, if the speech delay is associated with physical injury or unexplained growth failure, it is reasonable to conclude that it is "likely" that home circumstances are responsible for both deficiencies."

This conclusion is given added weight by our experience that abused children with retarded speech almost always show spectacular improvement in foster homes. We have not seen a child show regression of speech development while fostered. It is exciting to see previously virtually non-speaking children blossom with adequate stimulation and care.

We see no reason to modify our view that delay in speech, a term which we believe to be plain English, in no way imprecise, encompassing retardation of language, understanding, and expression, is a common finding in children who have been abused. We refer all our cases for assessment to speech therapists, whom we believe are aware of all the undoubted pitfalls in deciding that speech deficiencies are probably due to lack of stimulation or deprivation. We have found that in a group of 239 abused children over 1 year of age $48(20 \%)$ were found to have sufficiently retarded speech to warrant active intervention. As a further large number of children were not tested for various reasons the true percentage of problems is even higher, perhaps as high as $30 \%$. We are also finding that a large proportion are running into major learning and behaviour difficulties. This hardly conjures up a picture of 'robustness' of speech development in the face of deprivation and abuse.

\footnotetext{
References

1 Hall D, Berger M, Hill P. Medical evidence in child abuse. Arch Dis Child 1987;62:98.
}

${ }^{2}$ Taitz LS, King J. Medical evidence in child abuse. Arch Dis Child 1986;61:205-6.

L S TAITZ

Children's Hospital,

Sheffield S10 2 TH

\section{Home monitoring in SIDS siblings}

Sir,

I was interested to read the letter from Dr Swift and the reply from Dr Emery et al on apnoea monitoring and cot death. ${ }^{1}$

I have experience of home monitoring of over 300 siblings of victims of sudden infant death syndrome (SIDS) during the past eight years in both Ontario, Canada, and the Grampian region of Scotland. Two of these siblings died while being monitored. ${ }^{2}$ As others have had similar experiences there is no doubt that these infants can die despite home monitoring equipment. There is no evidence yet available, however, for it to be stated categorically that such equipment does not save lives. As implied by Emery et al, incomplete retrospective surveys, such as the Californian study they quote, are prone to bias and thereby unacceptable as evidence. The only way to answer the question is by a properly controlled randomised study such as that presently being undertaken by Emery et al. ${ }^{3}$ Fortunately SIDS in a SIDS sibling is relatively rare, and it is therefore likely to take a further 15-20 years to complete this study at the present enrolment rate. I hope by that time there will be a deeper understanding of the causes of the sudden infant death syndrome.

Perhaps this is looking at home monitoring from the wrong angle. Ninety nine per cent of subsequent SIDS siblings will survive. Most parents of these children, however, are extremely anxious and may often wake their newborn infant or even keep vigil. Not only is such supervision extremely demanding and difficult for the parents to maintain, but the myoclonic jerks, irregular respiratory patterns, and other normal sleep related phenomena are disturbing to such parents. Under these circumstances I would agree with Dr Swift that home monitoring is a relatively cheap and reliable method of allaying parental anxiety. Even if this is purely a placebo effect, does it matter? If this is the case, however, then it would seem reasonable to choose a placebo that might just save the infant's life rather than one that is unlikely to do so.

Most paediatricians in the United Kingdom use the Graseby Dynamics MR10 monitor and there is no reason to suppose that this equipment is in any way dangerous to the child. False alarms are relatively rare and occur mostly during the first few weeks of monitoring. Frequent weighing also has 'false alarms' every time the infant fails to gain weight. In my experience there are rarely difficulties with the weaning of parents off monitoring equipment. 
In Ontario home monitoring was stopped at an average age of just under 8 months. ${ }^{2}$

Judging by the dozens of letters I have received over the years, most parents found home monitoring very effective in relieving their anxiety, despite having been warned that babies have died while on such equipment. Further evidence for this is that well over $90 \%$ of parents who have had one infant on home monitoring equipment request monitoring for their subsequent children.

\footnotetext{
References

1 Swift PG. Apnoea monitoring and cot deaths. Arch Dis Child 1987;62:98-9.

2 Bryan MH, Duffty P. Home monitoring in SIDS. In: Prakash O, ed. Critical care of the child. Dordrecht: Martinus Nijhoff, 1984:161-5.

3 Emery JL, Waite AJ, Carpenter RG, Limerick SR, Blake D. Apnoea monitors compared with weighing scales for siblings after cot death. Arch Dis Child 1985;60:1055-60.
}

P DuFFTY

Aberdeen Maternity Hospital, Aberdeen $A B 92 Z A$,

Scotland

\section{The school entry medical examination}

Sir,

Whitmore and Bax put forward a cogent argument for retaining and improving the school entry medical examination. ${ }^{1}$ They point out that a fairly high proportion of children do not receive satisfactory health surveillance during their preschool years and emphasise the importance of the child receiving health care in relation to his functioning in school.

It is disappointing that such a comprehensive assessment does not attempt to identify children with asthma, a condition that causes a great deal of avoidable disability in schoolchildren. Recent community based studies have shown that roughly one in nine primary schoolchildren will have had recurrent episodes of wheezing by the age of 8 and that many of these children will not have been diagnosed as having asthma. ${ }^{2}$ Failure to make the diagnosis of asthma is often associated with frequent absences from school, poor educational performance, ${ }^{3}$ and inappropriate or inadequate treatment. This state of affairs is particularly unfortunate with a condition that is so easily diagnosed and where effective treatment is so readily available.

There is no evidence that the management of childhood asthma is improving. Indeed, admissions to hospital continue to increase and the number of deaths from asthma in children and young adults has almost doubled over the past decade. ${ }^{4}$ It is apparent that unless the diagnosis is made treatment will not be given. School doctors and school nurses are in a unique position and could easily identify most children with asthma by including the simple question 'Has your child ever wheezed?'? in their interviews or questionnaires. While this would not solve the problems of underdiagnosis and undertreatment, it would at least be a useful first step.

\section{References}

1 Whitmore K, Bax M. The school entry medical examination. Arch Dis Child 1986;61:807-17.
2 Spcight ANP, Lee DA, Hey EN. Underdiagnosis and undertreatment of asthma in childhood. Br Med J 1983;286:1253-6. ${ }^{3}$ Anderson HR, Bailey PA, Cooper JS, Palmer JC, West S. Morbidity and school absence caused by asthma and wheezing illness. Arch Dis Child 1983;58:777-84.

4 Khot A, Burn R. Deaths from asthma. Br Med J 1984;289:557.

J M COURIEL

Booth Hall Children's Hospital, Manchester M9 $2 A A$

Drs Bax and Whitmore comment:

We are grateful for Dr Couriel's comments. We did not include in our account the details of our parent questionnaire/interview, in which we do of course make enquiries about the child's history of respiratory illness. Apart from examining the child we have been reviewing, since the publication of the papers Dr Couriel refers to, the management of asthma in all children we see in school. We did emphasise in the paper that discussion on the management of illnesses, including asthma, is very much a part of the school doctors' and nurses' task.

\section{Improvements in child resistant containers}

Sir,

In 1985 you published our paper that suggested that the voluntary agreement between the government and the pharmaceutical profession on child resistant containers had not resulted in a significant fall in accidental child poisoning in South Glamorgan. ${ }^{1}$ Since that time we have been approached about whether we had evidence whether blister (or unit) packs were as effective as child resistant containers in preventing accidental child poisoning. It has occurred to us that it is possible to use data within our paper to answer this.

We have compared the type of packaging used in the cases of accidental child poisoning in children under 5 years with solid dose prescribable medications (excluding aspirin and paracetamol) admitted to hospital in South Glamorgan for the years 1983, 1984, and 1985 with the type of packaging of similar medications in general use in South Glamorgan estimated by those handed into our pharmacy by patients admitted to our hospital in 1985 . We have added 1985 figures for poisoning admissions to those contained originally in our paper (Table).

Table Comparison of types of packaging used in cases admitted to hospital because of poisoning in 1983-85 and in the general population in 1985

\begin{tabular}{|c|c|c|}
\hline \multirow[t]{2}{*}{ Type of packaging } & \multicolumn{2}{|c|}{ Group in whom packaging used } \\
\hline & $\begin{array}{l}\text { Cases admitted to } \\
\text { hospital due to } \\
\text { poisoning }\end{array}$ & $\begin{array}{l}\text { General } \\
\text { population }\end{array}$ \\
\hline Child resistant container & 11 & 256 \\
\hline Blister or unit packs & 26 & 78 \\
\hline Ordinary container & 77 & 469 \\
\hline Unknown & 8 & 0 \\
\hline
\end{tabular}

